Authors' contribution:

A) conception and design of the study

B) acquisition of data

C) analysis and interpretation of data

D) manuscript preparation

E) obtaining funding

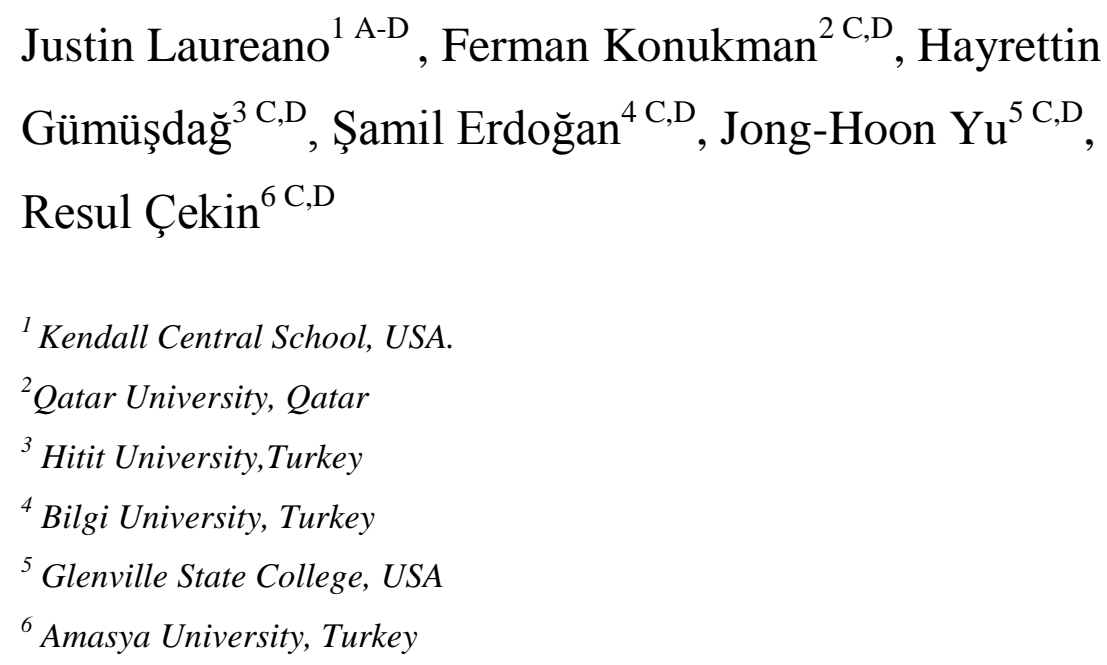

\title{
Effects of Marginalization on School Physical Education Programs: a Literature Review
}

ABSTRACT

The purpose of this research was to examine the causes of marginalization in Physical Education (PE) and to examine how PE teachers can counter the effects of this marginalization. Therefore, a recent literature review was conducted for the purpose of investigating the effects of marginalization. Four studies addressed feelings of burnout among PE teachers, including isolation, lack of equipment, and lack of space. Three research articles addressed communication with parents to encourage their support of PE. These three articles examined the use of PE websites as a tool to stay in constant communication with parents. In addition, one research study looked at how PE assessments needed to be consistent with other content areas and aligned with state and national standards. Moreover, one research article addressed the causes of parents' misconceptions of their children's PE programs. The final research article was a case study that related to how one teacher was able to change the parents' misconceptions about the PE programs. Results from this literature review study indicated that PE programs are being marginalized, yet there are ways for PE teachers to combat this issue.

KEYWORDS physical education, marginalization, school health policy

\section{Effects of Marginalization on School Physical Education Programs: A Literature Review}

Throughout the United States, there has been a surge of testing children at all grade levels and subjects. These tests have led to demands and requests for children and teachers to be more accountable for what they learn and what they teach, respectively. These tests have continued to show that children in the 
United States are falling below academic expectations compared to the rest of the world. Due to this fact, schools are spending large sums on areas of need. By spending more money on English Language Art and Math, compounded with the lack of funding that more schools are facing, school districts are being forced to reduce budgets in other areas. One area experiencing a large number of cuts is physical education (PE). This is not an issue that PE programs are facing only in our own country, but it is also a problem facing other countries around the world (Hardman, 2008).

Reductions are made to the teaching staff and equipment the program is receiving. Time when a gym can be used for PE classes is hindered, because it is used as a resource room or study room for other subjects (Kougioumtzis, Patriksson, \& Strahlman, 2011). Physical education teachers are being asked to take on more responsibilities outside their programs, such as lunch duties, study halls, etc., and are receiving less planning time for their own subject. In addition, physical education teachers are being degraded by their fellow teachers and looked at as if they were not "real teachers." This effect is called marginalization and is affecting physical education programs across the country. The physical education programs encouraged these cuts by not providing assessment results that show the programs' benefits, not grading their students on the same system as in the core subjects, not informing parents how physical education is different than when they attended school, and also by not being involved in all areas of their school communities (Sheehy, 2011).

The effects of marginalization on the teachers were devastating. Many teachers suffered from burnout or the feeling of being washed out. The teachers were developing lower self-efficacies and feelings that they are not needed to help their students be successful (Carlson \& Henninger, 2011). In addition, these teachers left the profession within the first five years of teaching.

Being physical education teachers, it is important to combat the marginalization of a subject that is so crucial for the health of youth suffering from childhood obesity. It is important for physical education teachers to be involved in school committees and events to gain the support of the other teachers. Given the rise of technology, the use of websites to give parents pertinent information about the program is a great avenue to gain parental support. The programs must also develop a sound curriculum that acts as a road map for not only the teachers but also the students (Carlson \& Henninger, 2011). Volunteering to mentor student teachers is another great way to learn new trends from not only the participant but also their college supervisors.

The pressure on teachers and budgets will not decrease with the implementation of the new Common Core Standards and Annual Professional Performance Reviews. It is time for physical education teachers to show that their subject is important for students and their health. Teachers must be the change agents and can no longer wait for someone else to initiate change. Family involvement can be a good solution for this issue. Physical Education teachers can contact parents, and they can come and support physical education courses with their skills. For example, parents can assist teaching biking, hiking, rock climbing, fitness, and team sports if they have any of these skills. In addition, fundraising and open house activities can contribute to physical education programs in many ways.

\section{Statement of the Problem}

Therefore, the purpose of this literature review was to examine two different questions. First, to examine what causes the marginalization of physical education programs throughout the country. Second, to determine methods physical education programs should implement to help decrease this marginalization.

\section{Methods}

The studies that were included for this literature review were located through Internet searches. We used the library database Academic Search Premier with some specific journal selections such as SPORTDiscus, Physical Education Index, and Education Research Complete. Through the databases we 
found 23 relevant articles that either focused on the causes of the marginalization of physical education or on how PE teachers can begin to decrease marginalization.

When beginning to search for relevant journal articles, we used a variety of different keywords such as Physical Education, Marginalization, Budget Reductions, Parental Involvement, Self Efficacy, Reductions, Burn Out, and Status. Many of these keywords were combined and used in various ways to locate the most relevant articles.

When choosing whether an article was relevant, we first checked the publication date of the research. Our search was delimited to peer-reviewed articles dated within the last 10 years. Once the first two criteria were met, we read the abstract of the article to determine its purpose and if this was a relevant question to our research. If the article was relevant, then we examined it closer to see if it fell under the causes of marginalization in PE or if it pertained to the effects of marginalization in PE.

Next, we began to categorize the results based on where they would best fit throughout the review. If the article was not relevant, we set it aside in case we needed it later or if it offered solid background knowledge that would fit the introduction. The main research articles that formed the critical mass of the research were summarized in various aspects of the research. These included the author/date, the purpose of the study, stating who the participants were in the study, what was measured, how the results were measured, what type of analysis was done on the data collected, the results of the study, and what conclusions were reached throughout the study.

\section{Results}

Parents' Perceptions of Their Children's PE Program

In a case study, Sheehy (2006) described parents' perceptions of their children's fifth-grade physical education programs. Three main research questions were asked throughout this study:

a) What information did the parents have about their children's fifth-grade PE program;

b) From what source did that information come?;

c) What sources appeared to be most and least credible to parents?

In the Sheehy's (2006) study, 27 parents were interviewed (23 females and 4 males). The parents would be classified as working middle class, and 11 of them had actually attended the same school. The PE teacher "Kelly" taught a developmentally and instructionally appropriate K-6 program. At the beginning of a school year, she would send a letter home to parents informing them of the days their children would attend $\mathrm{PE}$, expectations for behavior, and what type of clothing should be worn when they attended PE. This was the only formal communication between her and the parents during a school year unless parents asked about their children's grade. The school also had no formal program for getting parents involved in any aspect of the PE program.

The following were conducted in order to collect data for this research: parents completed a demographic questionnaire and participated in formal open-ended interviews; field observations were conducted at the school; document analysis of formal school policies was completed; and informal conversations were held with participants who attended school events. The interviews were done over two sessions that lasted for an hour. These interviews were immediately transcribed and reviewed to categorize data.

The results showed that a majority of parents knew who their child's teacher was, yet could not shed much light on what exactly they did in class. Only 18 parents knew how often their child attended PE during a week. Parents stated that the grading system for PE (S, N, or U) was only used in subjects that were "nonacademic" and therefore nonessential. Another pattern that emerged was that each parent made statements involving incorrect information concerning the PE program. These incorrect statements caused parents to unknowingly base judgment of their children's PE program on information that was incomplete, inaccurate, and obsolete. Many parents stated they only heard about PE if something "really exciting" or 
something their child disliked happened. For $67 \%$ of the parents, their child was the primary source of information about PE and was perceived as the most credible source as well. Most parents were unable to provide detailed information about their child's PE program. All of the parents drew on their own recollections of PE classes to fill in gaps where they lacked information of their children's program. Parents also indicated several specific signals showing that the school did not value PE such as the grading system used, lack of information they received from their child's teacher, and an open house format that stressed fun not academics.

\section{Causes of Burnout in PE Teachers}

Teaching and coaching are two different occupational roles, and teachers who also coach have stressful work environments common to all educational settings, but each occupational role has specific stress and burnout problems. The responsibilities of PE teachers and coaches are distinguishable from one another. These different roles and role conflicts may create stress among PE teachers who also coach. The history of physical education shows that there are contextual factors that promote PE teacher-coach role conflict (Konukman, Agbuga, Erdogan, Zorba, Demirhan \& Yilmaz, 2010). However, there has been little research investigating burnout among physical education teachers. In their article, Brouwers, Tomic and Boluijt (2011) examined the relationships between job demands, job control, social support, and perceived self-efficacy on the one hand and teacher burnout on the other hand. Their study aimed to examine workload, level of job control, and also social support as determinants of burnout among PE teachers.

The participants in this study were PE teachers that were employed in secondary education in the Netherlands. The researchers selected a random sample of 500 from the total of 4594 teachers. From the large group, the researchers picked one in nine male and female teachers. Out of the 500 teachers selected, 311 completed and returned the questionnaires. The researchers used the Dutch version of the Maslach Burnout Inventory for a teacher, which is divided into three sub-scales:

a) Emotional exhaustion,

b) Depersonalization,

c) Personal accomplishment.

The teachers could assign scores ranging from "never" to "always" when they rated each question. The questionnaires were mailed to the home addresses of the randomly selected PE teachers, the purpose was explained, and an envelope with a stamp was included. Once the results were received, computer analysis was used and a five-factor model was formulated to fit the data.

From this study, it was found that teachers who were able to control their job demands felt less emotional exhaustion than teachers who could not control their work environment. It was also found that the correlation between job demands and depersonalization was direct and dependent on teachers' control over how they worked. When the PE teachers felt they had a lack of control over the areas of their field, they were more likely to feel a sense of "burnout" when compared to teachers who felt they had some sort of control in their professions.

In a different study, Curtner-Smith (2010) examined whether PETE programs influenced the perspectives and practices of first year teachers and how those first year teachers viewed the profession they chose. This study was a continuation of similar research done on the same topic.

The participant in this study was "Ed", a 24-year-old white male, who was in his first year of teaching $\mathrm{PE}$ in a rural high school (grades 10,11, and 12) near which he grew up. He involved in teaching because he took great interest in sports and loved working with others.

During the first year of teaching, the researchers used three qualitative techniques to collect data:

a) Journal writing,

b) Formal/informal interviews,

c) Document analysis. 
"Ed" also videotaped a small sample of his lessons to provide the researcher with examples of his instruction. The journal writing was a reflective journal that was emailed and was supposed to answer the main question of the story of his experience as a PE teacher. The journal entry was supposed to be written once a week to describe any relevant experiences, how well-prepared he felt for his first year of teaching, and to try to identify the workplace factors which were influencing the way he taught. The first interview was completed three months after "Ed" had started his job and then also at the completion of his first year of teaching. Both of these interviews were taped and transcribed for analysis. During the interviews, "Ed" was asked about his perspectives regarding teaching PE, the extent to which his PETE program influenced his perspectives, and the workplace factors which influenced his teaching and how he reacted to these factors. On five occasions during his first year, "Ed" was interviewed on the phone to gain biographical information. The researchers also looked at various teaching items including lesson plans, evaluations, and materials he created. Triangulation was used to establish trustworthiness, and then the data was cross-checked for accuracy. All interviews and journals were analyzed to find themes that emerged and also discrepancies that were noted.

From this research, "Ed" found out that the facilities at his school were outstanding and the equipment was plentiful, yet he did say that his schedule was hectic and he was required to teach in different places every period. While most teachers were only responsible for $6 / 7$ sections of teaching, he was responsible for 11 sections of PE and also 4 sections of wellness. This led to an enormous amount of planning, and normally he was asked to share the gym, which was very stressful. Neither did the schedule allow him to teach units the way he felt they should be taught to benefit the students. The scope of what he taught was also narrowed, thus making it difficult for proper evaluation. "Ed" tried to keep contact with mainstream education teachers and also stay involved in the whole school. He stated that it was difficult to get to know the rest of the staff because he was "so young" and also because the PE department was separated from the rest of the school. He found it irritating that for everyone who gave him words of encouragement there were just as many comments and actions to belittle PE, including saying that his job was to teach sports and it should be okay for students to miss his class to take a test or work on a project.

According to "Ed," his PETE program and student teaching prepared him well for the field he chose to enter. He looked forward to changing aspects of his teaching for the second year, staying focused on what was important, and also tried to stay away from the negative aspects of teaching.

In a different research article (Taheri, Forouzandeh, Zameni \& Seddighi, 2012), researchers wanted to compare the burnout and job stress between physical education teachers and industrial workers. Burnout in this study was defined as the result of consistent stress, and was considered to be a sense of physical, mental, and emotional stress. Burnout syndrome involves three main symptoms of emotional fatigue, depersonalization, and a sense of powerlessness to do routines.

A total of 50 PE teachers and 60 workers of a textile factory were involved in this study. Each of the participants completed a burnout questionnaire and a stress questionnaire. The job stress questionnaire consisted of 20 items on a Likert scale that ranged from "never" to "always." The Jackson Burnout Inventory was also used to examine burnout and consisted of 22 items with three subscales of emotional exhaustion, depersonalization, and personal accomplishment. The participants first arranged items according to the dimension of frequency and secondly referred to the intensity of burnout pertaining to every statement. To determine validity and reliability, the researchers used the Cronbach's alpha formula and determined the reliability to be $\alpha=0.91$.

The data showed that there was a significant relationship between job stress and the subscales of burnout. That means that high levels of emotional exhaustion, depersonalization, and lack of personal accomplishment are associated with high levels of job stress. Burnout disorder was witnessed among counselors, teachers, and social workers who were associated with provocative stimuli such as having to deal with too many clients at the same time, lack of time, and also lack of support or appreciation. The study 
showed that the industrial workers suffered from less burnout and job stress than PE teachers. The research also showed that burnout will eventually decrease the efficiency and job satisfaction in employees.

Additional research was done concerning burnout levels of teachers in the secondary school setting (Koruklu, Feyzioglu, Ozenoglu, \& Aladag, 2012). The focus of their study was to examine burnout levels of secondary education teachers in terms of several variables. These variables were demographics, (subject, age, sex, seniority, type of school, and faculty), their opinions about changing curriculum, relationships with administration/colleagues, academic level of students, and their training. Participants in this study were chosen from 5323 secondary education teachers during the 2009-2010 school year. In the overall sample, 238 were females and 288 were males ranging in age from as young as 20 years to older than 40 years.

The study was done using a descriptive survey model to define the present situation. The researchers also used the Maslach Burnout Inventory (MBI), which approaches burnout through three subscales: emotional exhaustion, depersonalization, and personal accomplishment. The participants also completed a personal information form, which asked about sex, age, faculty from which they graduated, a type of school in which they worked, and their seniority. On the personal information sheet, there were also semi-structured questions about their opinions on new curriculum; teacher's relationships with colleagues, students, parents, administration; the student's academic levels; the school's physical and economic conditions; and the amount of training in which they participated. The qualitative data gathered was changed into quantitative data by using a point system associated with the varying categories. The data gathered from the burnout scale was analyzed using a one-way multivariate analysis of variance.

The results revealed that teachers who were younger showed higher levels of burnout than teachers who were over 40 . This could be because teachers over 40 felt they had less personal accomplishments than the teachers under 40 . The researchers also found significantly less burnout in teachers with more seniority when compared to teachers with less seniority; this was attributed to young teachers being unfamiliar with how to handle the stressful situations that accompany teaching. Teachers that stated they had a positive relationship with other colleagues, administration, parents, and students had significantly less burnout than teachers who felt those relationships were strained for whatever reason. Another cause of higher burnout was found in teachers that lacked proper equipment and proper facilities to teach properly.

\section{The Use of a PE Website/School Health Policy to Enhance Parent's Knowledge}

Knowing that parental involvement plays a crucial role in a child's education, teachers are continually searching for new and efficient ways to increase parental involvement in their subject area. Wilkinson and Scneck (2003) investigated the effects of a physical education website on parental knowledge of the program.

The participants in the study were 94 parents of seventh-grade students. The students attended four physical education classes and two health classes that were taught by the same teacher. The participants were asked to complete a pre-website questionnaire that used the Likert scale statements $(1=$ strongly disagree to $4=$ strongly agree). The questionnaire was mailed to the parents in a self-addressed stamped envelope. There were also open-ended questions to gain information concerning parents' access to the internet/email as well as current knowledge of physical education class activities, assignments, and their child's progress. The questionnaire also evaluated the parents' attitudes toward information on the website that they thought would be of value to them.

The same parents then completed a post-website questionnaire that measured the same aspects as the pre-web questionnaire. The only difference in the post-web interview was that the parents recorded the frequency in which they visited the website. The responses to the open-ended questions were typed and a content analysis was completed. The responses were sorted and coded according to different topics. The responses were then peer debriefed to identity categories and similar content. 
The results showed that $79 \%$ of parents believed that it would be important for them to see their child's class schedule, assignments, study guides, projects, and grades. The parents also stated that they wanted to see ways to communicate with the teacher. Researchers found four themes that emerged from the questionnaires: assessment, assignments, content for interest, and program knowledge. Parents wanted a website that was easy to navigate, allowed for easy/open communication with the teacher, and allowed them to follow their child's growth.

In a similar study done by Hill, Tucker, and Hannon (2010), the use of websites on physical education classes was evaluated. The purpose of this study was to determine the prevalence of website utilization and the components of website use in middle and high school physical education programs.

The researchers evaluated 285 websites in two Southern California counties. They created a checklist of what features and information a website should have to benefit the people using it. The checklist was generated after reviewing a variety of websites, reviewing literature, and also interviewing current physical education teachers. The checklist was validated for content by five physical education department heads that have websites for their programs and by five physical education teachers in the middle/high school setting. The checklist was to evaluate content and design features by looking at content, control, consistency, and accountability.

Researchers found that only 50 out of the 285 schools had an active physical education department website. Most lacked important content, and only listed the teachers' names and emails. The websites lacked phone numbers, information about the teacher, a picture of the teacher, and fitness information. The websites did not give detailed information about homework assignments, course descriptions, and links to other important websites that may be of interest to parents. In light of the push for standards-based instruction, one shocking result was the lack of access to these standards on the websites.

Implications from this study should encourage teachers at the secondary level to create a welldesigned website to promote the profession of physical education and their department's program. The information on the website needs to be easily distributed and readily available to students, teachers, and parents to encourage communication. The use of a website can create a positive image of the program and sends a message of teacher competence.

A study by Michael, Dittus, and Epstein (2007) examined how family and community involvement in schools is linked to improvements in academic achievement of students, better school attendance, and improved school programs and quality. The National Network of Partnership Schools (NNPS) has classified six types of involvement in schools: parenting, communicating, volunteering, learning at home, decision making, and collaborating with the community.

Data was collected from all 50 states and the District of Columbia at public and private schools at all grade levels. The data was collected using the School Health Policies and Practices Study 2006 questionnaires. These questionnaires assessed topics such as family and community involvement in school health councils; promotion of school health programs; staff development; and family/community involvement in developing, communicating, and implementing school health policies. The data was collected through computer assisted telephone interviews and self-administered questionnaires. Each respondent was also sent a letter of invitation and packet of study-related material. These packets contained a paper copy of the questionnaire so that the respondents could prepare for the interview. They were also provided the toll free number with an access code to take the survey when it was convenient for them.

The data from the state level in this study was collected through a census which made it not weighted. The information from schools and classrooms were weighted two ways to produce national estimates. The first weights were appropriate for making inferences to schools and nationwide based on the aggregation of classroom data within each school; the second was appropriate for making inferences to required elementary/middle/high school classes nationwide.

In this study, it was found out that only $27.8 \%$ of districts and $21.1 \%$ of schools offered physical education or physical activity programs to families. It was also found that since the last study in 2000 there 
has been an increase in the number of health classes requiring students to do homework that involves the parents in discussions on health topics. It was also found that schools are doing a better job of communicating their programs to the parents in their district. In addition, the research also found that the availability of staff development had increased for PE teachers.

\section{Changes PE Teachers Can Make To Enhance Their Status}

Lux and McCullick (2011) analyzed how one exceptional elementary physical education teacher navigated her working environment as a teacher of a so-called marginal subject. Physical education teachers have expressed feelings of frustration about having limited access to resources and about continually struggling to be perceived in the same way as other teachers in different content areas.

The teacher had 27 years of teaching experience and was 45 years old. Her belief was that PE was to expose children to a variety of activities so that they will choose to be physically active and develop healthy habits that will stay with them for a lifetime. The school in which the study took place was a homogeneous elementary school with 750 students. The teacher participated in unstructured and semi -structured interviews. The interviews were done in the form of conversations and were mainly about the environment of the school while gaining perceptions of the other teachers and administration. The teacher also participated in six audio taped structured interviews, which lasted about an hour to gain information about her background, philosophies, and the school environment. Throughout the 11 weeks of data collection, the teacher also participated in multiple observations and recorded field notes. "Grace" also completed electronically four critical incident accounts for the purpose of eliciting specific examples of events which would speak directly to the research question.

This research indicated the techniques "Grace" used:

1. She nurtured exceptionally close bonds with non-school personnel such as parents, students, and the community. This allowed her to gain respect from her students, parents trusted her and confided in her, and other teachers wanted to develop similar relationships.

2. She was in active pursuit of tools and resources that she used to improve the quality of her program and strengthen the position of PE in the school. This meant getting planning time, teaching space, equipment, and instructional support from a paraprofessional during large classes. She made sure to display students' work and PE content.

3. "Grace" took the time to develop an unbreakable bond with her paraprofessional.

4. She made sure she aligned herself with similar perspectives and circumstances in her work environment. She would promote interdisciplinary teaching and would share this during school meetings. This helped promote a positive image of PE at her school.

The findings showed that the marginal status of PE in the school setting impacts the way that teachers feel about themselves and their jobs. This study shows that in addition to being a good teacher it is imperative for PE teachers to be diplomatic in their work environment and that being isolated in the gym is not a positive. Overall, the results show the need to implement changes in our country's PE programs in order to decrease the effects of marginalization. The results consistently revealed that a PE website is a largely contributing factor as is the use of sound assessments that are consistent with all content areas in decreasing the effects of marginalization.

\section{Discussion}

It is quite apparent that schools across the country are facing hardships and abundant stress. Through the research, it also became apparent that PE programs are suffering extreme marginalization compared to other subjects and that PE teachers are feeling a large sense of "burnout" early in their careers. One of the overlying themes that emerged through the research was that a parent's perceptions of their child's PE 
program were uninformed and skewed as to the reality of what was happening in the schools (Sheehy, 2006). In order to change the image of PE, PE teachers must first change the current misconceptions held by the parents, which are mainly based on their own experiences in PE as a child. Education as a whole has drastically changed over the course of time especially within the last 10 years. When parents are not receiving information on how these changes are affecting their children, they form opinions based on their own education as students (Sheehy, 2006).

In addition, Academic Service Learning (ASL) involvements may help physical education teacher candidates in early years, and they can understand the realities of the profession before graduation (Konukman \& Schneider, 2012). Non-traditional experiential learning offers students an opportunity via active community involvement and reflection (Stacey, Dale, \& Langer, 1997). Service learning is not volunteer work: it is a class oriented experience where students become involved in an organized service activity based on need of community. Students understand related course content and civic responsibility via a period of highly structured reflection (Hamner, 2002; Stevens, 2008). This experimental learning model is a way of learning through experience that students obtain and apply academic skills based on community needs and social problems.

In the four articles that were dealing with the causes of burnout among PE teachers, many common themes were found through the research. One theme was that many times PE teachers feel a sense of isolation from other teachers. This feeling of isolation was not due to the physical location of the gym, but more likely it was caused by the other teachers who did not value the PE teachers as educators and did not see why their programs were important to the students (Curtner-Smith, 2010). Many times these teachers were asked to take on other multiple responsibilities throughout the day, taking away from their planning time and ability to design sound assessments based on state and national standards. Some of the teachers in the study taught seven PE preps a day at various grade levels and were also being asked to take on additional health and wellness classes. Other causes of burnout found in the research lay in the lack of adequate facilities and equipment for themselves and for their students. One article did, however, focus on teachers across the board and found that the feeling of "burnout" is affecting teachers of all subjects due to the pressures, constant curriculum changes, and large amounts of assessments. This study showed that the younger teachers under the age of 40 years feel much higher levels of burnout than teachers who are over 40 years and close to retirement.

There were three research articles alone that examined parental involvement in PE through communication; mainly by using a website. All three articles established how crucial it is for PE programs to be in constant communication with parents about their programs, goals, assessments, and also the standards their children need to meet (Hill, Tucker, \& Hannon, 2010). It was found in all three articles that parents had misconceptions about their child's PE programs and would benefit from the use of a website to relay information to them on a daily basis. Parents who were questioned during the studies stated that they wanted websites that were easy to navigate and had the information to communicate directly on the first page of the website (Wilkinson \& Scneck, 2003). In one of the research articles, it was found that when parents were well informed as to what their child was learning and what was supposed to be doing, the parents were more involved with their assignments for that class and willing to help with projects (Michael, Dittus, \& Epstein, 2007).

Another theme that emerged through the research was the need for PE teachers to administer to their students sound assessments based on state and national standards. Physical Education teachers need to utilize assessments to further their instruction; not just as a tool to calculate a grade. The other main theme that emerged when looking at assessments was the manner in which PE grades were communicated to parents. When the grading systems used in PE are different from the one used in other core content areas, people are led to believe that PE is not as valued by the teachers and administration. All grading systems in schools should be consistent from subject to subject so as to not portray one as more important than the other. 
There was also one case study done throughout this research that focused on how one teacher dealt with the effects marginalization had on PE in her school and how she tried to combat these effects. The teacher made everyday changes that completely altered the views of her program by students, parents, administrators, and also other teachers. This teacher was involved in her school, participated in committees, and asked how she could reinforce classroom concepts in the PE program (Lux \& McCullick, 2011). She demonstrated care for all academic areas and not just her own. Additionally, she cared about the school as a community and as a whole. This teacher took time to relate to her students and build a sense of trust with them and their parents. Communication was her greatest tool and she maintained open communication with everyone. "Grace" devoted her time and effort to make sure she had the equipment her students needed to be successful. She also fought for what she felt she deserved such as planning time, proper assessment tools, proper equipment, and the space she needed to properly teach students in a safe environment (Lux \& McCullick, 2011).

There are some limitations when it comes to researching marginalization in PE. Generally, this is a more recent issue affecting PE programs; thus, relevant research is not in abundance yet. Nor is there much research on how to counteract the effects of marginalization on PE. Most of the research done has been qualitative in nature and has not yielded a great deal of data in the form of numbers, which makes it hard to draw statistical information to compare findings.

\section{Conclusion}

Physical education programs are being marginalized across our country and throughout the world for a variety of reasons. Some of these reasons can be attributed to the financial strain many districts are facing in the overwhelming context of the Common Core Standards and new APPR guidelines. Yet there are also just as many other factors for which PE teachers are not taking responsibility and are not taking steps to change. Steps need to be taken by PE teachers if their programs are to be valued as a subject necessary for our children to participate in at school. Parents, teachers, administrators, and students alike need to view PE as important for children's physical health and leading them to better test scores in time.

Schools are being forced to make budget cuts, and PE teachers are feeling a great deal of the repercussions that come with these choices. In the research, teachers stated a lack of facility space and a lack of adequate equipment. PE teachers are asked to cover other positions such as study halls and lunch duty, thus giving up their planning time (Curtner-Smith, 2010). When teachers lack planning time, it becomes hard to always plan lessons that are geared towards state and national standards and that take prior assessments into account.

In this study, peer-reviewed research on the causes of marginalization and on ways in which PE teachers can decrease this marginalization were analyzed. Based on the findings from these studies, it is crucial for PE teachers to constantly communicate with parents because most parents have huge misconceptions concerning PE. This needs to be done through a PE website that is easy to navigate and that readily communicates available information, state requirements, state and national standards, and grading systems (Wilkinson \& Scneck, 2003). Parents need a solid understanding of what their child is doing in PE and how it helps their child not only in physical but also in mental health.

The research has also shown that to decrease marginalization in PE, the assessments need to be reformed to align with state and national standards. Assessments need to be easily understood with the presentation of objectives. The teacher's job is to use this information to drive further instruction. It is also imperative that the grading system used in PE classes is the same as the grading system used for every other subject area.

It is important for PE teachers to break down the barriers they feel are present between them and other staff and reduce their sense of isolation. Even though PE teachers cannot always control their physical location to decrease feelings of isolation, it is important to change the aspects that are controllable. To do this, PE teachers need to be involved in what is happening at their school, belong to committees, offer 
assistance to reinforce content subjects in PE, and also show they care about the well-being of their students (Lux \& McCullick, 2011).

In conclusion, it is crucial for more research to be conducted on how and if PE can enhance student test scores and their ability to learn new information. Teachers of PE need evidence that proves the benefits of healthy students and educate both content teachers and administration as to the importance of such health benefits. If it can be proven through research that physical activity during the school day helps students' brains to learn and retain information, schools will increase the minutes students participate in PE. In addition, this will enhance school tests scores and improve the reputation of the district in the eyes of their state. Moreover, this also leads to research on how childhood obesity affects students' ability to attend school and to learn new information in order to again cause an increase in PE. It is also imperative to continue research on ways to decrease marginalization and to determine if the use of websites and changing assessments can affect how PE is viewed as a subject.

\section{REFERENCES}

Brouwers, A., Tomic, W., \& Boluijt, H. (2011). Job demands, job control, social support and self-efficacy beliefs as determinants of burnout among physical education teachers. Europe's Journal of Psychology, (7)1, 17-39.

Carlson, K.B., \& Henninger, M.L. (2011). Strategies to increase the value of physical educators in k-12 schools: Physical educators can halt the marginalization through a quality curriculum, assessment, continued professional development, and advocacy. Journal of Physical Education, Recreation and Dance, 82(2), 17-39.

Curtner-Smith, M.D. (2001). The occupational socialization of a first-year physical education teacher with a teaching orientation. Sport, Education and Society, 6(1), 81-105.

Hardman, K. (2008). Physical education in schools: A global perspective. Kinesiology, 40(1), 5-28.

Hamner, D.M. (2002). Building bridges: The Allyn \& Bacon student guide to service-learning. Needham Heights, MA: Allyn \& Bacon.

Hill, G.M., Tucker, M., \& Hannon, J. (2010). An evaluation of secondary physical education websites. Physical Educator, 67(3), 114-127.

Konukman, F., Agbuga, B., Erdogan, S., Zorba, E., Demirhan, G., Yilmaz, I. (2010). Teacher-coach role conflict in school-based physical education in USA: a literature review and suggestions for the future. Physical Education \& Sport, 54(2), 59-64.

Konukman, F., \& Schneider, R. (2012). The Role of Academic Service Learning in Physical Edcation Teacher Education: Serving for The Community in $21^{\text {st }}$ Century. STRATEGIES, 25(7), 15-18.

Koruklu, N., Feyzioglu, B., Ozenoglu-Kiremit, H., \& Aladag, E. (2012). Teachers' burnout levels in terms of some variables. Educational Science: Theory \& Practice, 12(3), 1823-1830.

Kougioumtzis, K., Patriksson, G., \& Strahlman, O. (2011). Physical educations teachers' professionalization: A review of occupational power and professional control. European physical education review, 17(1), 111-129.

Lux, K., \& McCullick, B.A. (2011). How one exceptional teacher navigated her working environments as the teacher of a marginal subject. Journal of Teaching Physical Education, 3, 358-374.

Michael, S., Dittus, P., \& Epstein, J. (2007). Family and community involvement in schools: Results from the school health policies and program study 2006. Journal of School Health, 77(8), 567-587.

Schneider, R.C., Konukman, F., \& Stier, F.W. (2010). Survival Strategies for Physical Educators During Recessionary Times. The Physical Educator. 67(4), 170-177.

Sheehy, D.A. (2006). Parents' perceptions of their child's $5^{\text {th }}$ grade physical education program. Physical Educator, 63(1), 30-37.

Sheehy, D.A. (2011). Addressing parents' perceptions in the marginalization of physical education: The influence of parents- over policymakers, other parents, and their children's attitudes - cannot be ignored. The Journal of Physical Education, Recreation and Dance, 82(7), 42.

Stacey, K., Rice, D.L., \& Langer. G. (1997). Academic Service Learning Faculty Development Manual. Eastern Michigan University, Office of Academic Service Learning. Ypsilanti, MI.

Stevens, C.A. (2008). Service Learning for Health, Physical Education, and Recreation: A step by step guide. Champaign, IL: Human Kinetics.

Taheri, M., Forouzandeh, E., \& Seddighi, Z. (2012). Comparison of burnout and job stress between physical education employees and industrial workers. Annals of Biological Research, 3(3), 1242-1246. 
Wilkinson, C., \& Schneck, H. (2003). The effects of a school physical education and health web site on parental knowledge of the program. Physical Educator, 60(3), 162-168.

AUTHOR'S ADDRESS: $\quad$ Ferman Konukman

College of Arts and Science

Sport Science Program

Qatar University

P.O. Box 2713, Doha-QATAR

Email: fkonukman@qu.edu.qa 